\title{
Pain Control and Opioid Use in ICU should be a Quality Parameter
}

\author{
Sunil K Garg ${ }^{1} \odot$, Pragya Garg² ${ }^{2}$ \\ Indian Journal of Critical Care Medicine (2021): 10.5005/jp-journals-10071-23979
}

Dear Sir,

One day during a meeting with the hospital management, it emerged that the use of opioid analgesics in intensive care unit (ICU) of our hospital is more in comparison to other hospitals, and the idea was to reduce its consumption. This was in response to the issue raised by us regarding the inadequate availability of the same.

I was surprised since we consider pain control as one of the quality parameters in ICU. In fact, there is no definition of more or less, and it depends on the context, patient population under consideration, and hospital practices since pain control practices are not uniform across different hospitals, settings, and patient population. I explained that we deal with trauma patient more than any other hospitals, and pain control in our ICU is based on pain assessment scoring, and inadequate pain control leads to undesirable side effects.

Pain is defined as an unpleasant sensory and emotional experience associated with actual or potential tissue damage. Severe pain negatively affects patient status (e.g., cardiac instability, respiratory compromise, and immunosuppression) in critically ill adults, and the implementation of assessmentdriven and standardized pain management protocols improves ICU outcomes.

Pain management in ICU is a complex and consistent approach to pain assessment, and the management is paramount given the unique features of critically ill adults that include impaired communication, altered mental status, mechanical ventilation, procedures and use of invasive devices, sleep disruption, and immobilization. ${ }^{1}$ The reference standard measure of pain is a patient's self-report; the inability to communicate clearly does not negate a patient's pain experience or the need for appropriate pain management. ${ }^{2}$ Validated "Behavioral pain scale" provides measures for pain assessment in those patients unable to self-report.

Critically ill adults experience moderate to severe pain at rest ${ }^{3}$ and during standard care procedures. ${ }^{4}$ Pain management should be considered before any sedative agent is considered. To implement it, anglosedation is recommended, which is defined as either analgesia-first sedation (i.e., an analgesic, usually an opioid, is used before a sedative to reach the sedative goal) or analgesiabased sedation (i.e., an analgesic, usually an opioid is used instead of a sedative to reach the sedative goal).

Opioids remain a mainstay for pain management in most ICU settings. Though efficacious, there are safety concerns as well, so careful titration of analgesic dosing is important when balancing the benefit versus the potential risk of opioid exposure. ${ }^{5-9}$ 1,2Department of Critical Care, NMC Healthcare, Dubai, United Arab
Emirates

Corresponding Author: Sunil K Garg, Department of Critical Care, NMC Healthcare, Dubai, United Arab Emirates, Phone: +91-11-22334455, e-mail: sucare12@yahoo.co.in

How to cite this article: Garg SK, Garg P. Pain Control and Opioid Use in ICU should be a Quality Parameter. Indian J Crit Care Med 2021; 25(10):1205-1206.

Source of support: Nil

Conflict of interest: None

Nonopioid analgesics, such as acetaminophen, nefopam, ketamine, lidocaine, neuropathic agents, and nonsteroidal anti-inflammatory drugs (NSAIDs), have been evaluated in critically ill adults with the aim of sparing opioid use and improving analgesic effectiveness. On the basis of the current guidelines, all these medications are recommended in combination with opioids, not as a standalone except nefopam, which can be used as an adjunct or replacement to opioids in critically ill adults. ${ }^{10}$ Guidelines suggest COX-1-selective NSAIDs should not be used routinely as an adjunct to opioid therapy for pain management in critically ill adults, and there are concerns with the availability of nefopam.

Control of pain is a priority in critically ill adults, and it improves outcomes. To achieve it, opioids are the mainstay medications in ICU, and all other pain management medications are used as an adjunct only. Additionally, analgesia should be considered before sedation in critically ill adults. Pain control and, therefore, the use of opioid analgesics should be considered as a quality indicator in ICU.

\section{ORCID}

Sunil K Garg @ https://orcid.org/0000-0001-9710-8736

Pragya Garg @ https://orcid.org/0000-0003-4673-5910

\section{References}

1. The Joint Commission: new and revised standards related to pain assessment and management. 2017. Available at: https://www. jointcommission.org/assets/1/18/Joint_Commission_Enhances_ Pain_Assessment_and_Management_Requirements_for_ Accredited_Hospitals 1.PDF [Assessed January 5, 2018].

2. Merskey H, Bogduk N. Task force on taxonomy of the international association for the study of pain: classification of chronic pain: descriptions of chronic pain syndromes and definitions of pain terms. Seattle, WA: IASP Press; 1994.

(c) The Author(s). 2021 Open Access This article is distributed under the terms of the Creative Commons Attribution 4.0 International License (https://creativecommons. org/licenses/by-nc/4.0/), which permits unrestricted use, distribution, and non-commercial reproduction in any medium, provided you give appropriate credit to the original author(s) and the source, provide a link to the Creative Commons license, and indicate if changes were made. The Creative Commons Public Domain Dedication waiver (http://creativecommons.org/publicdomain/zero/1.0/) applies to the data made available in this article, unless otherwise stated. 
3. Chanques G, Sebbane M, Barbotte E. A prospective study of pain at rest: incidence and characteristics of an unrecognized symptom in surgical and trauma versus medical intensive care unit patients. Anesthesiology 2007;107(5):858-860. DOI: 10.1097/01.anes.0000287211.98642.51.

4. Puntillo KA, Max A, Timsit JF. Determinants of procedural pain intensity in the intensive care unit. The Europain ${ }^{\oplus}$ study. Am J Respir Crit Care Med 2014:189(1):3947. DOI: 10.1164/rccm.201306-1174OC.

5. De Jong A, Molinari N, de Lattre S. Decreasing severe pain and serious adverse events while moving intensive care unit patients: a prospective interventional study (the NURSE-DO project). Crit Care 2013;17(2): R74. DOI: 10.1186/cc12683.

6. Georgiou E, Hadjibalassi M, Lambrinou E. The impact of pain assessment on critically ill patients' outcomes: a systematic review. Biomed Res Int 2015;2015:503830. DOI: 10.1155/2015/503830.
7. Puntillo KA, Naidu R. Chronic pain disorders after critical illness and ICU-acquired opioid dependance: two clinical conundra. Curr Opin Crit Care 2016; 22: 506512. DOI: 10.1097/MCC.0000000000000343.

8. Macintyre PE, Huxtable CA, Flint SL. Costs and consequences: A review of discharge opioid prescribing for ongoing management of acute pain. Anaesth Intensive Care 2014;42(5):558-574. DOI: 10.1177/0310057X1404200504.

9. Yi P, Pryzbylkowski P. Opioid induced hyperalgesia. Pain Med 2015;16;S32-S36. DOI: 10.1111/pme.12914.

10. John WD, Yoanna S, Celine G, Dale N, Arjen S, Pratik P. Clinical practice guidelines for the prevention and management of pain, agitation/sedation, delirium, immobility and sleep disruption in adult patients in the ICU. Crit Care Med 2018;46(9);825-873. DOI: 10.1097/ CCM.0000000000003299. 